\title{
Binge-watching (Netflix) product placement: \\ A content analysis on different product placements in Netflix originals vs. non-Netflix originals, and drama vs. comedy shows
}

\section{Guy Laban*}

Graduate School of Communication, University of Amsterdam,

Amsterdam, Netherlands

Guy.laban@glasgow.ac.uk

\section{Chamoetal Zeidler}

Graduate School of Communication,

University of Amsterdam,

Amsterdam, Netherlands
Eline Brussee

Graduate School of Communication,

University of Amsterdam,

Amsterdam, Netherlands

\begin{abstract}
$\underline{\text { Abstract }}$
The popularity of digital streaming platforms, such as Netflix, is gradually growing. While digital streaming platforms share similar economic interests as traditional producing and broadcasting companies, the two differ in operation and nature of consumption. These platforms constructed new means of consuming content, offering licensed and original content. This study describes and examines how product placements, a popular advertising strategy that integrates commercials in media entertainment content, are applied in an up-to-date digital environment. A content analysis was conducted of product placements in comedy and drama shows within Netflix originals and non-Netflix originals shows. The study results indicate that Netflix original shows include more product placements than non-Netflix original shows. Moreover, drama shows include more product placements than comedy shows, and these are more explicit and visual. Finally, it was found that product placements categories can be predicted by the genre of the show, but not by the production type.
\end{abstract}

$\underline{\text { Keywords }}$

Product placements, Streaming, Television studies, Content analysis, Netflix, Popular media, Advertising strategies

\section{Introduction}

Traditional television advertising is becoming a less popular strategy among marketers. The variety of options, video-on-demand and digital streaming platforms not only changed media entertainment consumption but also the nature of commercials in visual mediums (Gerber \& Rick, 2010; Dias \& Borges, 2017). A frequently used strategy to reach audience members through media entertainment content is product placements (Ferraro \& Avery, 2000). Product placements are defined as: "all paid attempts to influence audiences for commercial benefits using communications that project a non-commercial character, of which 
viewers may be unaware and therefore process such communications differently than they process commercial messages" (Park \& Berger, 2010, p. 429). Several studies indicated that product placements lead to more positive brand attitudes and higher purchase intentions in comparison to traditional advertising strategies (Gupta \& Lord, 1998; Wiles \& Danielova, 2009; Williams et al., 2011; Sung, de Gregorio \& Jung, 2009; Yang \& Roskos-Ewoldsen, 2007).

As television audiences are migrating from traditional television viewing to digital streaming platforms that are "binge" oriented (Gerber \& Rick, 2010; Dias \& Borges, 2017; Deloitte, 2015), these are demonstrating different watching patterns and accordingly streaming content is perceived and impact differently (e.g., Perks, 2014; Pittman \& Sheehan, 2015). Following the possible effects of binge-watching, it is assumed that product placements in content that is produced by a digital streaming platform (e.g., Netflix) will affect and be perceived differently than product placements in content produced by traditional broadcasters. Nevertheless, there is a lack of initial understanding regarding the nature of product placements in current media entertainment settings. Hence, this study is aimed at exploring the nature and application of product placements in an up-to-date media entertainment landscape and describe how product placements differ between production types (streaming-oriented vs. traditional) and genres (drama vs. comedy).

Thus, the following research question is proposed:

RQ: To what extent does product placement differ in Netflix original vs. non-Netflix original shows and in drama vs. comedy shows?

This research question is studied through a content analysis of different (comedy and drama) shows broadcasted on Netflix, produced by (or for) Netflix or by other producing companies.

\section{Literature review}

2.1. Product placements - nature and application

There are many ways in which a product placement could be placed in media entertainment content. According to d'Astous and Seguin (1999), product placement strategies can be classified into two types; implicit and explicit. An implicit product placement is not being formally expressed; it, therefore, plays a passive role. An explicit product placement is formally expressed and plays an active role. Explicit product placements are better recalled than implicit product placements (Ferraro \& Avery, 2000). Furthermore, product placement 
could be portrayed in three dimensions, which are visual (seeing the brand) verbal (hearing the brand) or both (Ferraro \& Avery, 2000).

\subsection{Streaming-oriented production}

Audiences are migrating from the television screen to digital streaming platforms, consuming content in the way that fits them (Pittman \& Sheehan, 2015). Streaming platforms as Netflix constructed new means of consuming content, offering licensed content and their original content. Since producing content is an expensive procedure, these digital platforms share similar economic interests as traditional producing companies (Dias \& Borges, 2017). Nevertheless, online streaming differs from traditional broadcasting in the means of operation. For example, Netflix does not have commercial breaks as part of their business model (Keating, 2012; Netflix, n.d.a). Moreover, Netflix produces original content, known as "Netflix Originals". To remain exclusive these are usually only available on Netflix's online television network (Netflix, n.d.a; Keating, 2012; Salmon, 2013). As the economic motives of both digital streaming platforms and traditional television production and broadcasting companies are similar, yet they differ in operations and nature of consumption (e.g., Perks, 2014; Pittman \& Sheehan, 2015), the first sub-question is aimed at exploring whether these differences are also portrayed in the way product placements are used and applied by these two different content providers. Hence, the first sub-question is as following:

Sub-RQ1: To what extent do the amount, strategy, and dimension of product placements differ between Netflix original and non-Netflix original shows?

\subsection{Product placements across genres}

Previous studies have been comparing the appearance and features of product placements in different genres. However, there is no cohesive answer regarding whether comedy or drama provide better settings for product placements. According to Park and Berger (2010), product placements were more frequent in comedy films, whereas Sapolsky and Kinney (1994) state that the appearance of product placements in drama and comedy films was equal. Ferraro and Avery (2000), however, state that product placements appeared more in drama in comparison to comedy shows. Different factors can explain a genre providing better or worse settings for product placements. Accordingly, to following sub-question is being asked:

Sub-RQ2: To what extent do the amount, strategy, and dimension of product placements differ between drama and comedy shows? 


\subsection{Product placements' product categories}

Product placements can portray many product types (e.g., Lee, Sung \& de Gregorio, 2011). Since there is a knowledge gap regarding the connection of a show's production type and genre with the product placement's represented product, the last sub-question is proposed:

Sub-RQ3: To what extent product placements' product categories can be predicted based on the production type and the genre of the show.

\section{Method}

\subsection{Sample and coding procedure}

A content analysis was conducted of shows that are available in the Netflix database.

Netflix Originals shows were chosen to represent digital streaming platforms' original content because of Netflix's dominance in the digital streaming content market (see Rainie, 2017; Waniata, 2018). A total of twelve shows were chosen according to the available information in the Netflix website (Netflix, n.d.c): three Netflix original comedy shows, three Netflix original drama shows, three non-Netflix original comedy shows, and three non-Netflix original drama shows. From each show, four episodes were randomly chosen, resulting in a total of 48 episodes. These were coded by three coders who together developed the codebook and were trained to identify product placements. Each coder coded a total of 24 episodes, of which twelve were for the inter-coder reliability test. A total of 368 product placements were found.

\subsection{Measurements}

Genre (drama vs. comedy) and the production type (Netflix Originals vs. other) were treated as dichotomous scales, based on the Netflix database (Netflix, n.d.b; n.d.c). Product placement categories were following the most prevalent product placement categories: beverages, food products and restaurant chains, automobile brands, clothes and shoes, and consumer electronics (La Ferle \& Edwards, 2006; Lee et al., 2011; McKechnie \& Zhou, 2003). The product placement's dimension was treated as a dichotomous variable (visual vs. verbal) based on Ferraro and Avery (2000). The category of "both" was eliminated, and accordingly when both dimensions were available the most prominent dimension was chosen. The product placement's strategy was treated as a dichotomous variable (explicit vs. implicit), based on d'Astous and Seguin (1999). The number of product placements per episode was 
counted after finishing the coding procedure. The reliability of all variables was good, ranging between Krippendorff's alpha $=.77$ and 1.

\section{Results}

\subsection{Amount}

To identify the differences between the amount of product placements in Netflix original and non-Netflix original shows, a paired-sample t-test was conducted. There were significantly more product placements in Netflix original shows $(M=.55, S D=.50)$ than in non-Netflix original shows $(M=.45, S D=.50), t(375)=1.97, p=.050,95 \% C I[.00, .20]$, with a small effect size, $d=.12$.

To identify the differences between the amount of product placements in drama and comedy shows, a paired-sample t-test was conducted. There were significantly more product placements in drama shows $(M=.62, S D=.49)$ than in comedy shows $(M=.38, S D=.49)$, $t(375)=-4.66, p<.001,95 \% C I[-.33,-.14]$, with a small to moderate effect size, $d=.21$.

\subsection{Strategy}

A binary logistic regression analysis was conducted; with production type (Non-Netflix Originals as the reference group) and genre (drama as the reference group) as independent variables, strategy (implicit as the reference group) as the dependent variable and controlling for the dimension (verbal as the reference group). Maximum Likelihood Estimation (MLE) indicate that the model fit, $\chi^{2}=19.89, \log$ Likelihood $=-240.22(\mathrm{BIO}=-250.17)$, Pseudo $R^{2}=$ $4 \%(.04), p<.001$. The model indicates that a product placement's strategy cannot be predicted according to the show's production type. However, a product placement's strategy was significantly predicted according to the show's genre; product placements in comedy shows are $46.28 \%$ less likely to be explicit than product placements in drama shows. The product placement's dimension was also found to significantly predict the product placement's strategy. Likelihood-ratio test indicates that genera significantly contribute to the model $(L R=7.09, p=.008)$. See Table 1 for the whole model. 
Table 1. Bivariate Logistic Regression results Model 1, and Model 2; Dependent variable: Product placement's strategy

\begin{tabular}{lcc}
\hline Variable & Model 1 & Model 2 \\
Odds Ratio & Odds Ratio \\
Production type & -0.00272 & 0.940 \\
& $(0.216)$ & $(0.206)$ \\
Dimension & $1.542^{* *}$ & $3.582^{*}$ \\
& & \\
Genre & $(0.497)$ & $(1.821)$ \\
& & $0.537^{* *}$ \\
Intercept & & $(0.127)$ \\
& & \\
\hline Pseudo. $R^{2}$ & $-1.757^{* * *}$ & $0.283^{*}$ \\
Log lik. & $(0.491)$ & $(0.149)$ \\
$N$ & 0.0256 & 0.0397 \\
\hline Standard errors in parentheses $* p<0.05,{ }^{* *} p<0.01,^{* * *} p<0.001$ & -240.2 \\
\end{tabular}

\subsection{Dimension}

A binary logistic regression analysis was conducted; with production type and genre as independent variables, dimension as the dependent variable and controlling for the strategy. MLE indicate that the model fit, $\chi^{2}=35.51$, Log Likelihood $=-95.60(\mathrm{BIO}=-113.36)$, Pseudo $R^{2}=16 \%(.16), p<.001$. The model indicates that a product placement's dimension cannot be predicted according to the show's production type. However, a product placement's dimension was significantly predicted according to the show's genre; product placements in comedy shows are $84.71 \%$ less likely to be visual than product placements in drama shows. The product placement's strategy was also found to significantly predict the product placement's dimension. Likelihood-ratio test indicates that genre significantly contribute to the model $(L R=21.89, p<.001)$. See Table 2 for the whole model. 
Table 2. Bivariate Logistic Regression results Model 1, and Model 2; Dependent variable: Product placement's dimension

\begin{tabular}{lcc}
\hline Variable & Model 1 & Model 2 \\
Odds Ratio & Odds Ratio \\
Production type & 0.336 & 1.150 \\
& $(0.375)$ & $(0.450)$ \\
Strategy & $1.542^{* *}$ & $3.582^{*}$ \\
& $(0.497)$ & $(1.821)$ \\
Genre & & $0.153^{* * *}$ \\
& & $(0.0683)$ \\
Intercept & & $19.12^{* * *}$ \\
& $1.711^{* * *}$ & $(8.468)$ \\
\hline pseudo $R^{2}$ & $(0.249)$ & 0.1566 \\
Log lik. & 0.0601 & -95.60 \\
$N$ & -106.5 & 368 \\
\hline Note. Standard errors in parentheses, ${ }^{*} p<0.05,{ }^{* *} p<0.01,{ }^{* * *} p<0.001$ &
\end{tabular}

\subsection{Category}

To predict the possibility of occurrence of different product placement's categories (with automobile brand being the reference group as the most prominent product placement category) based on the production company and the genre of the show, the strategy and the dimension of the product placement, a multinomial logistic regression analysis was conducted. The goodness of fit was assessed by conducting Hosmer-Lemeshow tests for each pair of groups. In no case was this test significant. The model was found significant $\chi^{2}(16)=$ $125.00, p<.001$, explaining 30.3 percent of the variance in the dependent variable,

Nagelkerke $R^{2}=.30$. The findings indicate that significant unique contributions were made by genre $\left(\chi^{2}(4)=46.71, p<.001\right)$, strategy $\left(\chi^{2}(4)=49.95, p<.001\right)$, and dimension $\left(\chi^{2}(4)=\right.$ $11.23, p=.024)$, on the category of the product placement. The producing company was not found to have a significant contribution to the model, $\chi^{2}(4)=153.46, p=.335$.

The genre of the show significantly predicted whether the product placement was a beverage or an automobile brand $\left(b=-1.62\right.$, Wald $\left.\chi^{2}(1)=24.28, p<.001\right)$, food product or an automobile brand $\left(b=-1.06\right.$, Wald $\left.\chi^{2}(1)=6.96, p=.008\right)$, and clothing brand or an automobile brand $\left(b=-1.73\right.$, Wald $\left.\chi^{2}(1)=11.28, p=.001\right)$. The odds ratio shows that as the show genre changes from drama to comedy, the change in the odds of the product placement being a beverage compared to being an automobile brand is .20 (5.00 times more than in a comedy show), food product compared to being an automobile brand is .35 (2.86 times more 
than in a comedy show), and clothing brand compared to being an automobile brand is .18 (5.56 times more than in a comedy show). See Table 3 for the whole model.

Table 3. Multinomial logistic regression, predicting product placements' categories.

\begin{tabular}{|c|c|c|c|c|c|}
\hline & \multirow[t]{2}{*}{ B } & \multirow[t]{2}{*}{ Wald } & \multirow[t]{2}{*}{$\mathrm{df}$} & \multicolumn{2}{|c|}{ 95\% CI for Odds Ratio } \\
\hline & & & & Odds Ratio & Lower, upper \\
\hline \multicolumn{6}{|c|}{ Beverages vs automobile brand } \\
\hline Intercept & $-.18(.37)$ & .23 & 1 & & \\
\hline Genre & $1.62^{* * *}(.33)$ & 24.28 & 1 & 20 & {$[.10, .38]$} \\
\hline Production type & $.01(.31)$ & .00 & 1 & 1.01 & {$[.55,1.83]$} \\
\hline Strategy & $1.45^{* * *}(.33)$ & 19.39 & 1 & 4.25 & {$[2.23,8.10]$} \\
\hline Dimension & $-1.35^{*}(.58)$ & 5.37 & 1 & .26 & {$[.08, .81]$} \\
\hline \multicolumn{6}{|c|}{ Food products vs automobile brand } \\
\hline Intercept & $-1.71^{* *}(.54)$ & 9.95 & 1 & & \\
\hline Genre & $-1.06^{* *}(.40)$ & 6.96 & 1 & .35 & {$[.15, .76]$} \\
\hline Production type & $-.09(.37)$ & .06 & 1 & .92 & {$[.44,1.88]$} \\
\hline Strategy & $2.07^{* * *}(.48)$ & 18.37 & 1 & 7.91 & {$[3.07,20.38]$} \\
\hline Dimension & $.20(.53)$ & .15 & 1 & 1.23 & {$[.43,3.47]$} \\
\hline
\end{tabular}

Clothing and shoe brands vs automobile brand

\begin{tabular}{lccccc}
\hline Intercept & $2.12^{* *}(.66)$ & 10.16 & 1 & & \\
Genre & $1.73^{* *}(.51)$ & 11.28 & 1 & .18 & {$[.07, .49]$} \\
Production type & $.50(.50)$ & 1.03 & 1 & 1.64 & {$[.629,4.298]$} \\
Strategy & $1.82^{* *}(.59)$ & 9.44 & 1 & 6.18 & {$[1.93,19.75]$} \\
Dimension & $-.48(.69)$ & .47 & 1 & .62 & {$[.16,2.42]$}
\end{tabular}

Consumer electronics vs automobile brand

\begin{tabular}{|c|c|c|c|c|c|}
\hline Intercept & $.85^{*}(.40)$ & 4.51 & 1 & & \\
\hline Genre & $.47(.37)$ & 1.59 & 1 & 1.60 & {$[.77,3.31]$} \\
\hline Production type & . $49(.29)$ & 2.86 & 1 & 1.63 & {$[.93,2.86]$} \\
\hline Strategy & $-.17(.29)$ & .35 & 1 & .84 & {$[.48,1.49]$} \\
\hline Dimension & $1.25(.80)$ & 2.42 & 1 & .29 & {$[.06,1.39]$} \\
\hline Nagelkerke $R^{2}$ & & & & & \\
\hline$N$ & & & & & \\
\hline
\end{tabular}




\section{Discussion and conclusions}

Netflix original shows are more likely to show more product placements than non-Netflix original shows. However, the two do not differ in terms of strategy and dimension. Drama shows are more likely to show more product placements than comedy shows and are more likely to show more explicit and visual product placements. Finally, product placements' categories can be predicted by genre, but not by the production type.

The results imply that people who often watch streaming oriented content, Netflix Originals in the context of this study, over content that is produced by traditional production companies can encounter more product placement. This is particularly interesting since both content types are aimed to be consumed differently (Perks, 2014; Pittman \& Sheehan, 2015). This could influence audience members and have certain persuasive consequences. However, the effect is unknown, and it is, therefore, important to further investigate it.

According to the uses and gratification theory (McQuail, Blumler \& Brown, 1972; Blumler \& Katz, 1974), people have different needs, and accordingly, they consume different kinds of media content to satisfy those needs. Thus, it could be said that different people are exposed to different, and more (or less) product placements according to their media entertainment consumption preferences. Whether it is the genre, the chosen platform, or the production type of the content that determines what one will watch, the amount of product placements one is exposed to relates to this initial decision.

Drama content could be perceived by producers as better settings for product placements. Beyond the fact that there are more product placements in drama than in comedy shows, the odds of a product placement being a certain category were higher in a drama show. Hence, it seems that drama content is perceived to provide better settings for a wider variety of products. This can determine by different factors and differences between the genres. For example, a drama show episode is usually longer than a comedy one. Also, there might be content-related features that provide better conditions for product placements in drama content. It emphasises the influence that genre has on the portrayal of product placements, and therefore, the effects of content-related features within different genres should be further explored.

In contrast to the genre, the production type of the show had no influence on the odds of a product placement being a specific category over another. In addition, the results explain that while the genre influences the strategy and dimension of the product placement, the 
production type does not. Hence, it can be concluded that while the type of production possibly influences the number of product placements in the show, genre plays a more substantial role in the essence and nature of the product placement; what it will portray and how.

Although some conclusions were made in this study on the difference between the two dimensions of visual and verbal, it is difficult to generalise it due to the low amount of verbal product placements that were found. The main question is, is it that verbal product placements were not recognised by the coders or is it that there simply are significantly more visual product placements than verbal. Regardless, the fact that there are many more visual product placements in shows could signify the extent of visual over verbal product placements. It could be said that visual product placements are often more noticeable and present within the scene, and it might prime the audience to keep the thought of the brand in their mind (Ratcliff \& McKoon, 1988).

For future research, it is recommended to consider content-features within genres. This study focused on the differences between comedy and drama, but other content-related features and themes, violent-content for example, could portray product placements differently. As different studies have mentioned (e.g., Wiles \& Danielova, 2009; Yang \& Roskos-Ewoldsen, 2007) product placements lead to more positive brand attitudes and higher purchase intentions compared to traditional television advertising strategies. Thus, investigating the effects of product placements within different production types (digital streaming vs. traditional) and genres on brand attitudes and purchase intentions is important to fully understand the role of product placements in the current media entertainment advertising landscape. While much can be said about the content of these shows, it is important to look at the audience as well, since these were made for an (active) audience that might or might not act upon these product placements.

\section{References}

Bolle, R. M., Yeo, B. L., \& Yeung, M. M. (1998). Video query: Research directions. IBM Journal of Research and Development, 42(2), 233-252. doi: 10.1147/rd.422.0233. Blumler, J. G., \& Katz, E. (1974). The Uses of Mass Communication: Current Perspectives on Gratifications Research. Beverly Hills, CA: Sage. 
Chan, F. F. Y. (2012). Product placement and its effectiveness: A systematic review and propositions for future research. The Marketing Review, 12(1), 39-60. doi: $10.1362 / 146934712 \times 13286274424271$.

d'Astous, A., \& Seguin, N. (1999). Consumer reactions to product placement strategies in television sponsorship. European journal of Marketing, 33(9/10), 896-910. doi: $10.1108 / 03090569910285832$.

De Gregorio, F., \& Sung, Y. (2010). Understanding attitudes toward and behaviors in response to product placement. Journal of Advertising, 39(1), 83-96. doi: 10.2753/JOA0091-3367390106.

Deloitte. (2015). Digital democracy survey: A multi-generational view of consumer technology, media and telecom trends. Digital Democracy Survey 9th Edition. Oakland, CA: Deloitte Development LLC.

Dias, E., \& Borges, F. (2017). A Discussion of Cultural Studies and Contemporary Television. Journal of Languages, Texts, and Society, 43, 44-60.

Ferraro, R., \& Avery, R. J. (2000). Brand appearances on prime-time television. Journal of Current Issues \& Research in Advertising, 22(2), 1-15. doi: 10.1080/10641734.2000.10505104.

Gerber, A., \& Mandler, R. (2010). TV for the twenty-first century: The video ad model in transition. In G. Einav (Ed.), Transitioned media: A turning point into the digital realm (pp. 9-38). New York, NY: Springer New York. doi:10.1007/978-1-4419-60993_2

Gupta, P. B., \& Lord, K. R. (1998). Product placement in movies: The effect of prominence and mode on audience recall. Journal of Current Issues \& Research in Advertising, 20(1), 47-59. doi: 10.1080/10641734.1998.10505076.

Karrh, J. A., McKee, K. B., \& McKee, C. J. (2003). Practitioners' evolving views on product placement effectiveness. Journal of advertising research, 43(2), 138-149. doi: 10.2501/jar-43-2-138-149.

Keating, G. (2012). Netflixed: The epic battle for America's eyeballs. New York, NY: Portfolio.

La Ferle, C. \& Edwards, S. M. (2006). Product placement: How brands appear on television. Journal of Advertising, 35(4), 65-86. doi: 10.2753/JOA0091-3367350405. 
Lee, T., Sung, Y., \& de Gregorio, F. (2011). Cross-cultural challenges in product placement. Marketing Intelligence \& Planning, 29(4), 366-384. doi:

10.1108/02634501111138545.

McKechnie, S. A \& Zhou, J. (2003). Product placement in movies: A comparison of Chinese and American consumers' attitudes. International Journal of Advertising, 22(3), 349374. doi: 10.1080/02650487.2003.11072858.

McQuail, D., Blumler, J. G., \& Brown, J. (1972). The television audience: A revised perspective. In D. McQuail (Ed.), Sociology of Mass Communication (pp. 135-65). Middlesex, England: Penguin.

Netflix (2017). Financial statements. Retrieved from https://ir.netflix.com/financials.cfm?CategoryID=282.

Netflix (n.d.a). Company profile. Retrieved from https://ir.netflix.com/.

Netflix (n.d.b). Home website. Retrieved from https://www.netflix.com/.

Netflix (n.d.c). Netflix media center. Retrieved from https://media.netflix.com/en/only-onnetflix\#/new?page=1.

Park, D. J., \& Berger, B. K. (2010). Brand placement in movies: The effect of film genre on viewer recognition. Journal of Promotion Management, 16(4), 428-444. doi: 10.1080/10496491003591261.

Perks, L. G. (2014). Media Marathoning: Immersions in Morality. New York, NY: Lexington Books

Pittman, M., Sheehan,K. (2015). Sprinting a media marathon: Uses and gratifications of binge-watching television through Netflix. First Monday, 20(10) doi:10.5210/fm.v20i10.6138

Rainie, L. (2017, September 13). 61\% of young adults in U.S. watch mainly streaming TV. Retrieved from http://www.pewresearch.org/fact-tank/2017/09/13/about-6-in-10young-adults-in-u-s-primarily-use-online-streaming-to-watch-tv/

Ratcliff, R., \& McKoon, G. (1988). A retrieval theory of priming in memory. Psychological Review, 95(3), 385. doi: 10.1037/0033-295X.95.3.385.

Salmon, F. (2013, June 13). Why Netflix is producing original content. Retrieved from http://blogs.reuters.com/felix-salmon/2013/06/13/why-netflix-is-producing-originalcontent/ 
Sapolsky, B. S., \& Kinney, L. (1994). You oughta be in pictures: Product placements in the top grossing films of 1991. In K. W. King (Ed.), Proceedings of the 1994 conference of the American Academy of Advertising (Vol. 89). Athens, GA: American Academy of Advertising.

Sternthal, B., \& Craig, C. S. (1973). Humor in advertising. The Journal of Marketing, 37(4), 12-18. doi: 10.2307/1250353.

Sung, Y., de Gregorio, F., \& Jung, J. H. (2009). Non-student consumer attitudes towards product placement: Implications for public policy and advertisers. International Journal of Advertising, 28(2), 257-285. doi: 10.2501/s0265048709200564.

Waniata, R. (2018, September 14). Netflix vs. Hulu vs. Amazon Prime: Battle of the Streaming Giants. Retrieved from https://www.digitaltrends.com/home-theater/beston-demand-streaming-services/

Wiles, M. A., \& Danielova, A. (2009). The worth of product placement in successful films: An event study analysis. Journal of Marketing, 73(4), 44-63. doi: 10.1509/jmkg.73.4.44.

Williams, K., Petrosky, A., Hernandez, E., \& Page Jr. R. (2011). Product placement effectiveness: revisited and renewed. Journal of Management and Marketing research, 7, 1-24.

Wouters, M., \& De Pelsmacker, P. (2011). Brand placement in scripted and non-scripted Belgian and US programs on Belgian prime time television. Journal of Marketing Communications, 17(5), 299-318. doi: 10.1080/13527261003600421.

Yang, M., \& Roskos-Ewoldsen, D. R. (2007). The effectiveness of brand placements in the movies: Levels of placements, explicit and implicit memory, and brand-choice behavior. Journal of Communication, 57(3), 469-489. doi:10.1111/j.14602466.2007.00353.x. 